
\title{
25 Research Square \\ Current Situation of Clinical Trials of Drugs for Children's Indications in China
}

\section{Lin Song}

Children's Hospital of Chongqing Medical University

\section{Sujuan Ran}

Children's Hospital of Chongqing Medical University

\section{Yuntao Jia}

Children's Hospital of Chongqing Medical University

\section{Bin Li}

Army Medical University

\section{Jin Xu}

Army Medical University

\section{Bennian Huo}

Children's Hospital of Chongqing Medical University

\section{Nange Yin}

Children's Hospital of Chongqing Medical University

\section{Maolin Ai}

Children's Hospital of Chongqing Medical University

\section{Yao Liu ( $\nabla$ swhliuyao@163.com )}

https://orcid.org/0000-0001-7507-2410

\section{Research article}

Keywords: Pediatric patients, Clinical trials, Pediatric indications, Drug Trial Registration and Information Publication Platform

Posted Date: June 29th, 2021

DOl: https://doi.org/10.21203/rs.3.rs-658961/v1

License: (9) This work is licensed under a Creative Commons Attribution 4.0 International License. Read Full License 


\section{Abstract}

Background: The number of pediatric outpatient visits in the general hospitals of China shows an increasing trend year by year. To analyze the current situation of clinical trials of drugs with indications for children in China in order to provide references for research and development of drugs for children and in formulating relevant policies.

Methods: Drug clinical trials with indications for children registered before January 9, 2020 were retrieved based on the drug clinical trial registration and information publicity platform. The data were extracted and statistically analyzed by excel 2010 and SPSS 22.0, respectively.

Results: There were 256 clinical trials of drugs with indications for children, which accounted for $2.61 \%$ of the total registered trials. The overall average annual growth rate of the number of trials from 2007 to 2019 was $43.30 \%(P=0.0000)$. The host company and the lead organization were mainly located in the eastern and northern parts of China. There were 67 trials (26.17\%) with children as subjects; 102 trials (39.84\%) with research drugs only for children; the drug type was mainly the chemical drug, and indications mainly included infections, nervous and mental diseases and respiratory diseases.

Conclusion: The prospects associated with pediatric drug development are positive, but it still needs new incentives or technical guidance to further promote.

\section{Background}

With the comprehensive implementation of the two-child policy on January 1, 2016, the birth rate of newborns in China has been significantly increased in the recent years. According to the 2019 China Health Statistics Yearbook [1], the number of pediatric outpatient visits in the general hospitals of China has reached to 270 million in 2018, with an increase of $107 \%$ from over 2009, showing an increasing trend year by year. The pediatric medical services are facing great challenges due to this increase. According to the White Paper on Drug Safety Investigation Report for Children in 2016, there were 176,652 domestic drug approvals by June 2016 , wherein only 3,517 (2\%) were of children. The lack of specific drugs and medication information for children in drug labels have always been the issues of concerns all over the world. Due to lack of information on pediatric medications in the drug labels, the off-label use of drugs is widespread in children. Previous studies have reported that the incidence of off-label medication use ranged from $28.3-46.5 \%$ in pediatrics [2-5]. The off-label drug use is associated with the occurrence of adverse drug events [6,7], posing a great hidden danger to medication therapy and patient safety [8]. Therefore, clinical research on pediatric drugs has been further strengthened in recent years.

Since 2011, a series of measures have been taken to encourage the research, development and production of specific drugs and their suitable dosage forms for pediatric patients in China [8]. In May 2014, the former State Health and Family Planning Commission and other six ministries and commissions have issued "Several Opinions on Safeguarding Drug Use for Children" (No.29 [2014] of the State Health and Family Planning Commission), setting forth specific requirements for safeguarding the 
drug use in children by encouraging research and development, speeding up the application and evaluation, and improving the system construction. The National Health Committee and other departments have issued three batches of pediatric drug lists for research and development by the end of 2019 [9]. With the encouraging measures, the number of clinical trial institutions qualified for conducting pediatric clinical trials in China has been significantly increased in recent years [8]. Thus, in this study, clinical trials of drugs with indications in children were analyzed in China to provide reference for research and development of pediatric drugs and formulation of relevant policies.

\section{Methods}

\section{Data source}

To strengthen the supervision and management of clinical trials of drugs, promote the openness and transparency of clinical trial information of drugs, protect the rights, interests and safety of subjects, the Medical Products Administration (NMPA) in China has established a web-based database for clinical trials. This is named as the Drug Trial Registration and Information Publication Platform, and was officially released in 2013. It is a national authoritative database of clinical trials in China, and all drug clinical trials being done including phase I to IV trials should be registered and the bioequivalence studies must be registered on the platform before enrolling the first patient. The NMPA then routinely crosschecks the information on the platform with the related data and summary report submitted with a given trial to ensure that the information is accurate and up to date. Retrospective registration is required for trials that started before 2013 , but is not completed for the related new drug applications.

Information about the registered drug clinical trial includes sponsor's information, such as the applicant name, contact information, etc.; trial's information, such as the name of the drug studying, indications, drug types, study purposes, trial design, subject information, inclusion and exclusion criteria; researcher's information, ethics committee approval information, trial status, etc. After retrieval, there are 9797 drug clinical trials registered on the platform as of January 9, 2020.

\section{Trials Screening And Data Extraction}

Trials with indications of "er" in pediatric patients in Chinese or "adolescent" were retrieved for inclusion. Two authors have respectively screened the retrieved trials, and excluded the repeated registration trials, trials that have been suspended, non-drug trials, and trials without indications for children. Two authors have reviewed the full information of all the included trials and extracted the study characteristics, and any disagreements were resolved through discussion or by consulting a third author. The following information of the trials, including registration number, trial status, trial phase, date of first ethical approval, name of the sponsor and province of the sponsor located, the first affiliation and province of the principal investigator located, number of research centers, name, type, dosage form and indications of the drug studied, age of the subjects, children's age specified in the indication, whether a data monitoring 
committee (DMC) have been established, and whether insurance had been purchased for participants, were recorded. We defined the first ethical approval date of the trials as the date of the trials to make annual trial number statistics. The provinces of the sponsor and the principal investigator were divided into seven regions according to the China's seven geographical divisions, the north, east, south, central, northeast, northwest and the southwest. For foreign sponsors, their registered province was recorded in China. For drugs with indications for adults and children, only the indications for only children were recorded. In this study, the indications of studied drugs were coded according to the International Statistic Classification of Diseases and Related Health Problems, Tenth Revision, International Classification of Diseases (ICD)-10 classification.

\section{Statistical analysis}

Descriptive analyses were used to summarize the data, frequency (percentage) was used for qualitative data, and median (range) was used for quantitative data. A simple regression model was used to analyze the trends in the number of trials included, with $\mathrm{P}<0.05$ representing a statistically significant difference, and the year of the trial was defined by the date of the first ethical approval. All statistical analyses were performed on a personal computer with the statistical package SPSS for Windows (version 22.0).

\section{Results}

A total of 347 clinical trials with indications including "er" of infant and child were retrieved in Chinese or "adolescent" were screened for inclusion. Of these, 77 trials were excluded due to duplications and repeated registrations, and 11 trials have been suspended, 2 non-drug trials, and one trial with indications not for children were excluded. Finally, there were 256 trials included for data extraction and analysis, accounting for $2.61 \%$ of the total registered number as of January 9,2020 .

\section{General characteristics of the trials with indications for children in China}

The general characteristics of trials with indications for children in China were shown in Table 1. Considering the 75 multiple-center trials, the number of centers was 8(3 377), and the trial with 377 centers was an international multiple-center phase $\otimes$ clinical trial. In addition, 11 of the 16 trials for which a data safety monitoring committee have been established were multiple-center clinical trials. Of the 256 trials, the initial registration date of the trial was from July 2, 2013 to January 7, 2020, and the first ethical approval date of the trials was from September 19, 2007 to December 26, 2019. By considering the first ethical approval date, the number and the phase of trials distributed in different years was shown in Fig. 1. 
Table 1

General characteristics of 256 trials with indications for children in China

\begin{tabular}{|ll|}
\hline Items & Frequency (\%) \\
\hline Trial status & \\
\hline Ongoing & $119(46.48 \%)$ \\
\hline Completed & $137(53.52 \%)$ \\
\hline Trial phase & \\
\hline Phase I & $18(7.03 \%)$ \\
\hline Phase II & $20(7.81 \%)$ \\
\hline Phase III & $35(13.67 \%)$ \\
\hline Phase IV & $14(5.47 \%)$ \\
\hline Bioequivalence & $160(62.50 \%)$ \\
\hline Others & $9(3.52 \%)$ \\
\hline Trial range & \\
\hline China & $247(96.48 \%)$ \\
\hline International & $9(3.52 \%)$ \\
\hline No. of centers & \\
\hline Single-centre trial & $181(70.70 \%)$ \\
\hline Multiple-centre trial & $75(29.30 \%)$ \\
\hline DMC had been establish & $16(6.25 \%)$ \\
\hline Insurance had been purchased & $98(38.28 \%)$ \\
\hline
\end{tabular}

A total of 67 trials (including 4 phase $\varangle, 20$ phase $\varangle, 26$ phase $\nabla$, and 11 phase $\nabla$ trials) were conducted among children age ranging from 0 to 18 years. Ten trials included both adults and children as subjects, and 179 trials (including all 160 bioequivalence trials) included only adults as subjects. A simple regression model revealed that the overall average annual growth rate of the number of trials was $43.30 \%$ $(P=0.0000)$. As shown in Fig. 1, the number of trials included had been significantly increased since 2017. In addition, a simple regression model based on the number of phases I to IV trials showed an average annual growth rate of $22.12 \%(P=0.001)$.

Geographical location of the trials with indications for children in China 
The geographical distribution of the sponsors of the 256 trials was shown in Fig. 2. More than $40 \%$ of the sponsors were located in the eastern China. The geographical distribution of the principal investigator involved in the 256 trials was shown in Fig. 3, and the trial institutions were mainly distributed in the east, the north and the central China, with Beijing, Jiangsu and Shanghai as the major ones.

\section{Distribution Of The Studied Drugs And Its Dosage Form}

The types of research drugs involved in the 256 trials and the distribution of the main dosage forms were shown in Fig. 4. The drug types mainly included were the chemical drugs, accounting for $76.17 \%$. Based on the age of indications, there were 102 drugs used for children under 18 years age, i.e. children-specific drugs (39.84\%), in which 3 drugs were used for premature infants and newborns, namely caffeine citrate, porcine lung surfactant and hepatitis $B$ vaccine, and 11 drugs were used for only infants. The remaining $154(60.16 \%)$ drugs were indicated for both adults and children. Considering the dosage forms of the 195 chemical drugs, tablets were the main ones, followed by capsules, injections and granules. The other dosage forms were shown in Fig. 4 included syrup, powder, oral solution membrane and needle-free percutaneous injection administration system, respectively. All traditional Chinese medicine/natural drugs were special drugs for children, and their dosage forms mainly included granules and patches. Of the 40 kinds $(15.63 \%)$ of biological products, 33 were specific drugs for children, mainly in the form of injections.

\section{Distribution Of The Indications Of The Research Drugs}

According to ICD-10, the organ system of diseases related to the indications was shown in Fig. 5. Among them, 92 drugs (35.94\%) were indicated for infections, followed by neurological, psychiatric and respiratory diseases. Of the 92 clinical trials with indications to infection, 26 were digestive system infections and 22 were respiratory system infections.

\section{Discussion}

The Drug Trial Registration and Information Publication Platform was started to operate in November 2012 but was not officially applied until 2013, and the clinical trials included in this study did not completely incorporate the clinical trials that obtained approval documents before 2012. Besides, the purpose of this study was to analyze the clinical trials of drugs with indications for children, and reflect the research and development situation of drugs for children in China, so we included studies with indications for children but apparently some of the studies were carried out in adults, although the drugs were indicated for children.

According to the retrieval results, there were still very few drugs $(2.61 \%)$ for pediatric indications in the clinical trials of registered drugs that are currently carried out in China, and only 67 trials $(26.17 \%)$ with children as subjects, only 102 trials (39.84\%) with research drugs only for children. As a special and vulnerable group, recruitment and ethical issues make the conduction of clinical trials in children more 
challenging. How to further improve or innovate the technical methods of clinical trials, improve the use of efficient databases such as electronic medical record system, and strengthen the cooperation among industries, administrative departments, medical institutions, research doctors and subjects, to further promote the development of clinical trials of pediatric drugs and the application of data, has long been a problem of discussion [10]. On January 3, 2020, the State Drug Administration has issued the Notice of State Drug Administration on Guiding Principles for Issuing Real World Evidence to Support Drug R\&D and Evaluation (Trial) (No.1, 2020) [11]. This pointed out that in areas of drug use for children, the use of real-world evidence is warranted to support the expansion of indications as this is also one of the situations where drug regulatory decisions may be applicable. This provides a new direction for research and development of drug use in children based on real-world evidence.

For a long time, the research and development of drugs and their preparations have mainly focused on adults and their associated diseases, and further development of drugs suitable for children of different ages has faced a great challenge [12]. In this study, the dosage forms of chemical drugs were still mainly tablets and capsules, which are commonly used by adults. Studies have shown that even small infants can take small doses of solid dosage forms, such as micro tablets [13]. In addition, other oral mucosal absorption dosage forms, such as orally disintegrating films, are also expected to become new dosage forms suitable for children [12]. Among the clinical trials included in this study, only montelukast sodium has the dosage form of orally soluble film. In terms of age for indications, of the 256 trials included in this study, 3 drugs were used for premature infants and newborns, and 11 drugs were used for infants only. Studies have shown that the incidence rate of off-label use of drugs in newborns was about $90 \%$ [14], and clinical trials in young children are facing greater ethical challenges, especially the sick newborns and premature infants, and might require new incentives or relevant policies to select the drugs that are mostly needed for research in trial design and development [15].

A great progress has been made in the study of drug use for children worldwide in recent years. Studies have shown that in the past 15 years, a total of 1,200 pediatric studies have been submitted to the U.S. Food and Drug Administration. More than 700 drug specifications have been revised and information on pediatric use has been provided. In addition, the failure rate of pediatric clinical trials has been decreased from more than $40 \%$ to about $20 \%$ [16]. In terms of quantity, the clinical trials of drugs with indications for children in China are increasing year by year, but excluded the bioequivalence trials, and the phases $\otimes$ to osclinical trials were still less than 20 every year. In addition, there are still large regional differences between the sponsors and research institutions, with obvious advantages in the east and the north.

\section{Conclusion}

How to further promote children's clinical research based on the existing policies, narrow the differences between the east and the west, and develop specific drugs that are suitable for children, especially for young children, still requires the introduction of new policies, relevant incentives and technical guidelines. In general, the prospects in pediatric drug development are positive. The drug demand for a more flexible 
and individualized drug administration for children with significant improvement and development is warranted in the near future.

\section{Abbreviations}

NMPA

Medical Products Administration; DMC:Data monitoring committee; ICD:International Classification of Diseases.

\section{Declarations}

\section{Acknowledgements}

The authors have no acknowledgements to make.

\section{Funding}

This work was supported by the Science and Technology Research Projects of Chongqing (No. cstc2020jsyj-zzysbAX0024). The funding body had no role in the design of the study and collection, analysis, and interpretation of data and in writing the manuscript.

\section{Availability of data and materials}

The datasets used and/or analyzed during the current study are available from the corresponding author on reasonable request.

\section{Authors' contributions}

YL, LS, SR and YJ designed this study, BL, JX and BH assessed studies for inclusion and collected data, MA and NY did the data analysis and interpretation, LS and YL managed and wrote the manuscript, all the authors took part in the discussions of the results and contributed to editing of the manuscript.

\section{Ethics approval and consent to participate}

No specific ethical approval was sought for this study.

\section{Consent for publication}

Not applicable.

\section{Competing interests}

The authors declare that they have no conflicts of interest in their authorship or publication of this paper.

\section{References}


1. National health commission. 2019 China health statistics yearbook. Beijing, China Union Medical College Press (2019). p. 128.

2. Joret-Descout P, Prot-Labarthe S, Brion F, Bataille J, Hartmann JF, Bourdon O. (2015). Off-label and unlicensed utilisation of medicines in a French paediatric hospital. Int J Clin Pharm. 2015,37(6), 1222-1227. https://doi.org/10.1007/s11096-015-0191-3.

3. Knopf H, Wolf IK, Sarganas G, Zhuang W, Rascher W, Neubert A. Off-label medicine use in children and adolescents: results of a population-based study in Germany. BMC Public Health. 2013;13(1):631. https://doi.org/10.1186/1471-2458-13-631.

4. Corny J, Bailey B, Lebel D, Bussières JF. Unlicensed and off-label drug use in paediatrics in a motherchild tertiary care hospital. Paediatr Child Health. 2016;21(2):83-7. https://doi.org/10.1093/pch/21.2.83.

5. Slažneva J, Kovács L, Kuželová M. Off-label drug use among hospitalized children: identifying extent and nature. Eur Pharm J. 2012;59(1):48-54.

6. Eguale T, Buckeridge DL, Verma A, Winslade NE, Benedetti A, Hanley JA, et al. Association of off-label drug use and adverse drug events in an adult population. JAMA Inte Med. 2016;176(1):55-63. https://doi.org/10.1001/jamainternmed.2015.6058.

7. Pratico AD, Longo L, Mansueto S, Gozzo L, Barberi I, Tiralongo V, et al. Off-label use of drugs and adverse drug reactions in pediatric units: a prospective, multicenter study. Curr Drug saf. 2018;13(3):200-7. https://doi.org/10.2174/1574886313666180619120406.

8. Wu W, Tang Z, Chen J, Gao Y. Pediatric drug development in China: Reforms and challenges. Pharmacol Res. 2019 10;148. https://doi.org/10.1016/j.phrs.2019.104412.

9. General office of the national health commission. General office of the ministry of industry and information technology, general department of the state administration of food and drug administration. (2019). http://www.gov.cn/zhengce/zhengceku/2019-11/18/content_5453049.htm. [Accessed March 30, 2020].

10. Tsukamoto K, Carroll KA, Onishi T, Matsumaru N, Brasseur D, Nakamura H. (2016). Improvement of pediatric drug development: regulatory and practical frameworks. Clin Ther. 2016, 38(3), 574-581. https://doi.org/10.1016/j.clinthera.2016.01.012.

11. China food and drug administration. China food and drug administration circular on guidelines for publishing real-world evidence to support drug development and review (trial). (no. 1, 2020) (2020). http://www.nmpa.gov.cn/WS04/CL2138/373175.html. [Accessed March 30, 2020].

12. Preis $M$, Breitkreutz J. Pediatric drug development and dosage form design. AAPS PharmSciTech. 2017;18:239-40. https://doi.org/10.1208/s12249-016-0705-x.

13. Klingmann V. Acceptability of mini-tablets in young children: Results from three prospective crossover studies. AAPS PharmSciTech. 2017;18(2):263-6. https://doi.org/10.1208/s12249-016-0639-3.

14. Yen E, Davis JM, Milne CP. Impact of regulatory incentive programs on the future of pediatric drug development. Ther Innov Regul Sci. 2019;53(5):609-14. https://doi.org/10.1177/2168479019837522. 
15. Ward RM, Benjamin DK, Davis JM, Gorman RL, Kauffman R, Kearns GL, et al. (2018). The need for pediatric drug development. J Pediatr. 2018(192), 13-21.

https://doi.org/10.1016/j.jpeds.2017.08.011.

16. Green DJ, Zineh I, Burckart GJ. Pediatric drug development: outlook for science-based innovation. Clin Pharmacol Ther. 2018;103(3):376-8. https://doi.org/10.1002/cpt.1001.

\section{Figures}

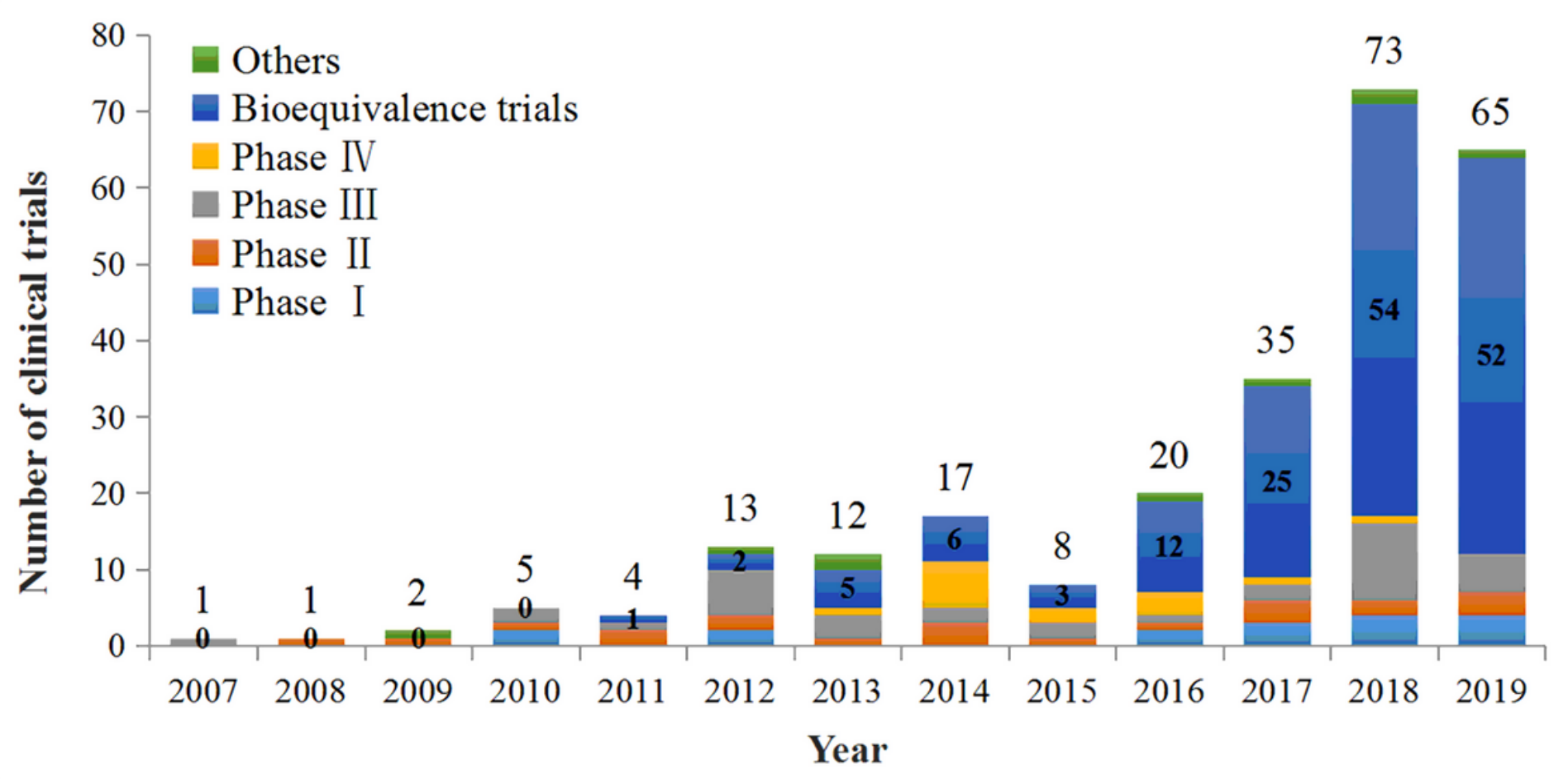

\section{Figure 1}

Number of clinical trials of drugs with indications for children in China from 2007 to 2019 (Dark blue represents the number of bioequivalence trials, and the upper end of the column is marked as the total number) 


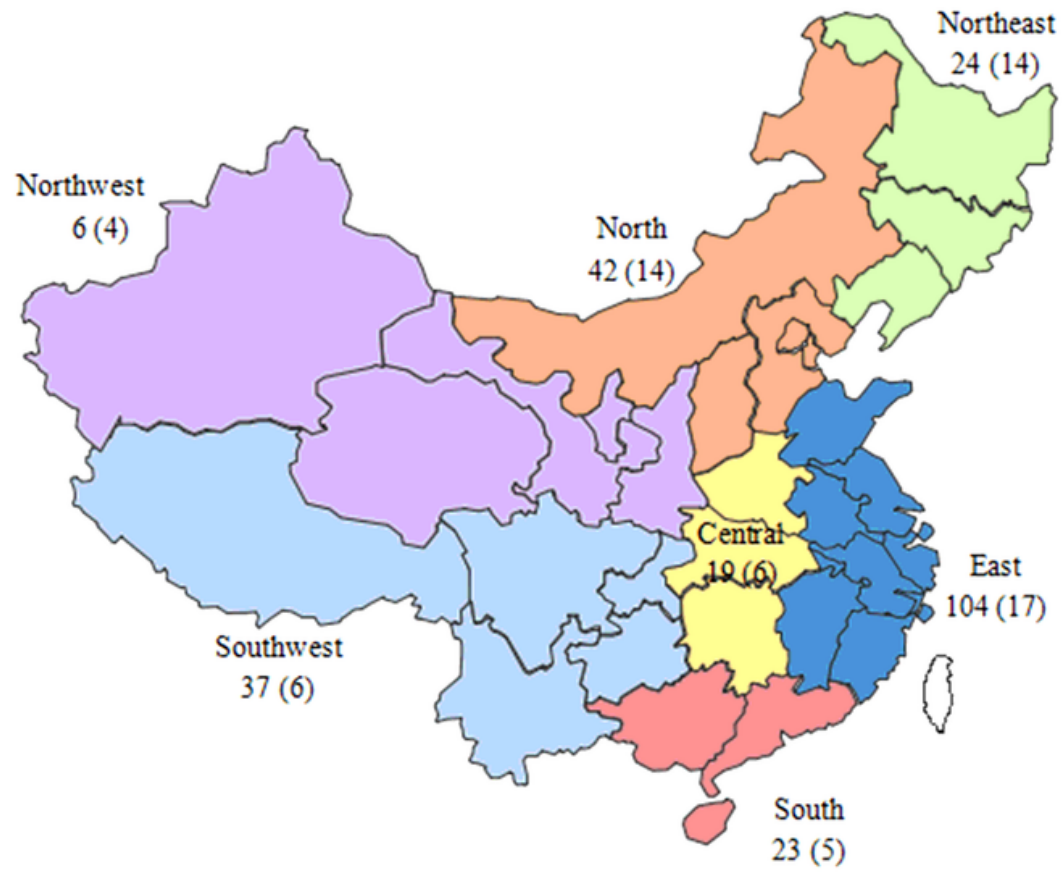

Region and Number of trials Region and Number of trials province (trials in children) province (trials in children)

\begin{tabular}{lclc}
\multicolumn{3}{c}{$\mathrm{n}=256(67)$} & $\mathrm{n}=256(67)$ \\
\hline Central & $\mathbf{1 9}(6)$ & East & $104(17)$ \\
Henan & $0(0)$ & Zhejiang & $17(0)$ \\
Hubei & $17(5)$ & Jiangsu & $34(7)$ \\
Hunan & $2(1)$ & Shandong & $12(0)$ \\
Northe ast & $\mathbf{2 4 ( 1 4 )}$ & Shanghai & $24(6)$ \\
Liaoning & $3(0)$ & Fujian & $4(1)$ \\
Jilin & $19(13)$ & Anhui & $11(2)$ \\
Heilongjiang & $2(1)$ & Jiangxi & $2(1)$ \\
Northwest & $\mathbf{6 ( 4 )}$ & North & $\mathbf{4 2 ( 1 4 )}$ \\
Gansu & $3(2)$ & Beijing & $30(13)$ \\
Shanxi & $2(1)$ & Hebei & $5(0)$ \\
Xinjiang & $1(1)$ & Tianjï & $7(1)$ \\
Ningxia & $0(0)$ & Shanxi & $0(0)$ \\
Qinghai & $0(0)$ & Neimenggu & $0(0)$ \\
Southwest & $\mathbf{3 7}(6)$ & South & $\mathbf{2 3}(5)$ \\
Sichuan & $25(6)$ & Guangdong & $17(4)$ \\
Chongqing & $6(0)$ & Guangxi & $1(0)$ \\
Guizhou & $1(0)$ & Hainan & $5(1)$ \\
Yunnan & $5(0)$ & Taibei & $\mathbf{1 ( 1 )}$ \\
\hline
\end{tabular}

\section{Figure 2}

Geographical distribution of trial sponsors Note: The designations employed and the presentation of the material on this map do not imply the expression of any opinion whatsoever on the part of Research Square concerning the legal status of any country, territory, city or area or of its authorities, or concerning the delimitation of its frontiers or boundaries. This map has been provided by the authors.

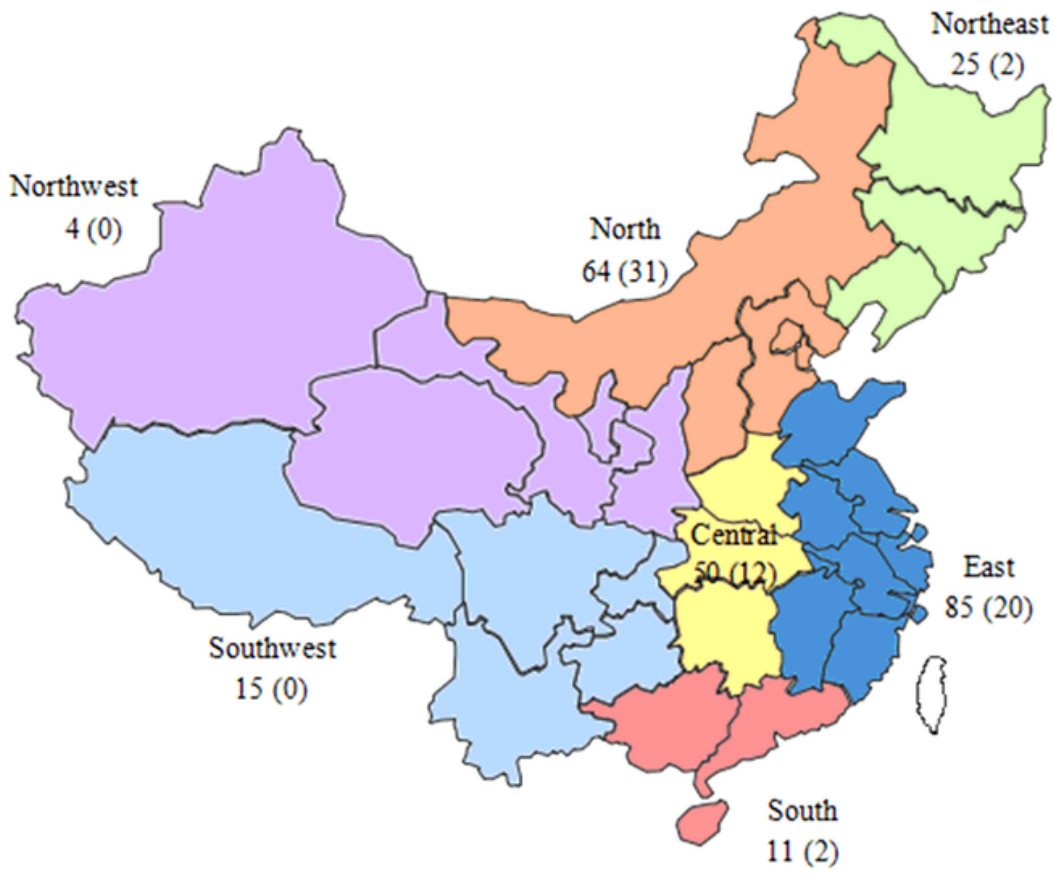

\begin{tabular}{|c|c|c|c|}
\hline $\begin{array}{l}\text { Region and } \\
\text { province }\end{array}$ & $\begin{array}{c}\text { Number of trials } \\
\text { (trials in children) } \\
\mathbf{n = 2 5 5}(67)\end{array}$ & $\begin{array}{c}\text { Region and } \\
\text { province }\end{array}$ & $\begin{array}{c}\text { Number of trials } \\
\text { (trials in children) } \\
\mathbf{n = 2 5 5}(67)\end{array}$ \\
\hline Central & $50(12)$ & East & $85(20)$ \\
\hline Henan & $13(2)$ & Zhejiang & $15(5)$ \\
\hline Hubei & $18(9)$ & Jiangsu & $24(6)$ \\
\hline Hunan & $19(1)$ & Shandong & $8(0)$ \\
\hline Northeast & $25(2)$ & Shanghai & $27(8)$ \\
\hline Liaoning & $14(1)$ & Fujian & $4(1)$ \\
\hline Jilin & $11(1)$ & Anhui & $5(0)$ \\
\hline Heilongjiang & $0(0)$ & Jiangxi & $2(0)$ \\
\hline Northwest & $4(0)$ & North & $64(31)$ \\
\hline Gansu & $3(0)$ & Beïing & $38(15)$ \\
\hline Shanxi & $0(0)$ & Hebei & $8(2)$ \\
\hline Ximjiang & $1(0)$ & Tianjin & $17(14)$ \\
\hline Ningxia & $0(0)$ & Shanxi & $1(0)$ \\
\hline Qinghai & $0(0)$ & Neimenggu & $0(0)$ \\
\hline Southwest & $15(0)$ & South & $11(2)$ \\
\hline Sichuan & $8(0)$ & Guangdong & $4(0)$ \\
\hline Chongqing & $4(0)$ & Guangxi & $3(2)$ \\
\hline Guizhou & $0(0)$ & Hainan & $4(0)$ \\
\hline Yunnan & $3(0)$ & Taibei & $1(0)$ \\
\hline
\end{tabular}

Figure 3 
Geographical distribution of principal investigators Note: The designations employed and the presentation of the material on this map do not imply the expression of any opinion whatsoever on the part of Research Square concerning the legal status of any country, territory, city or area or of its authorities, or concerning the delimitation of its frontiers or boundaries. This map has been provided by the authors.

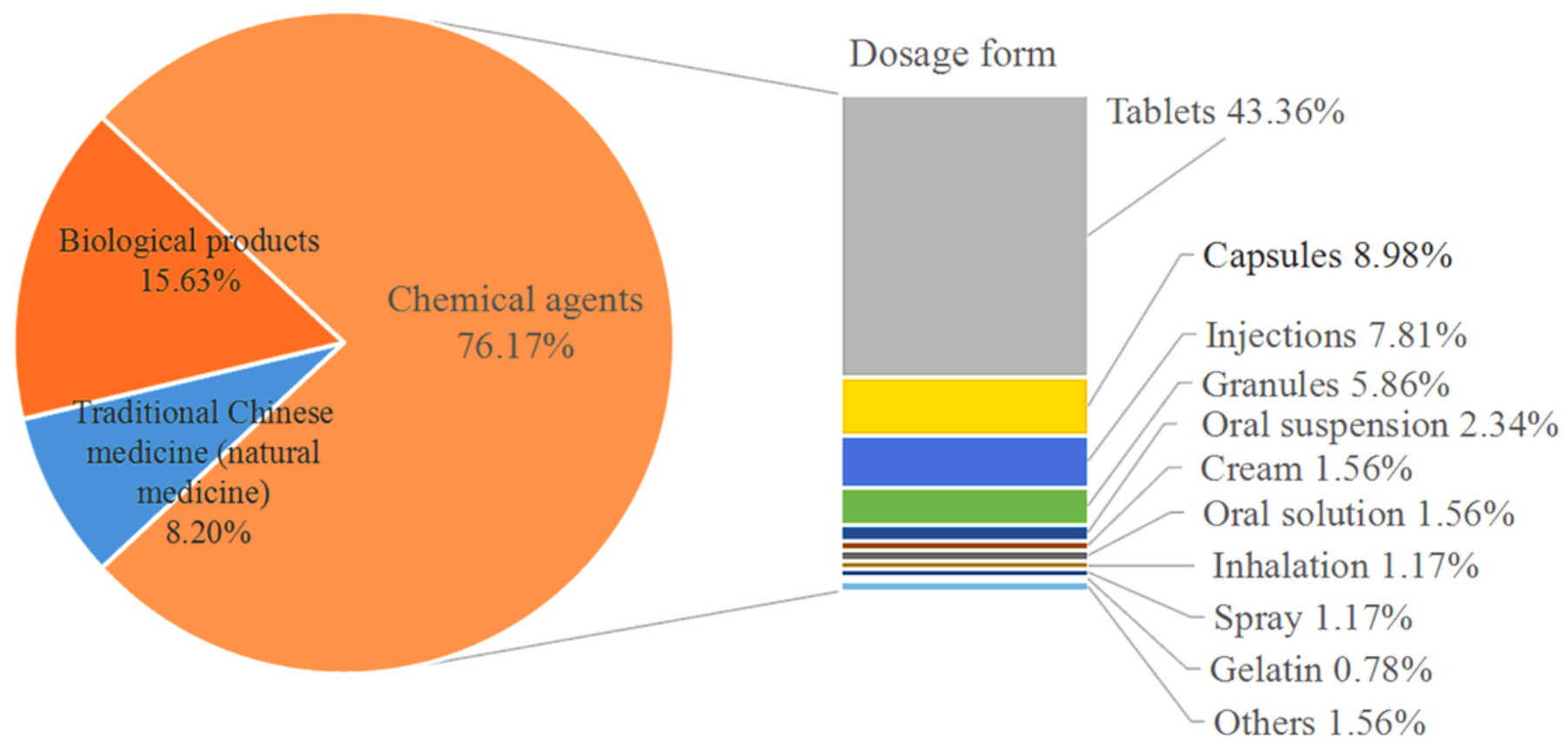

\section{Figure 4}

Drug types and main dosage forms of research drugs $(n=256)$

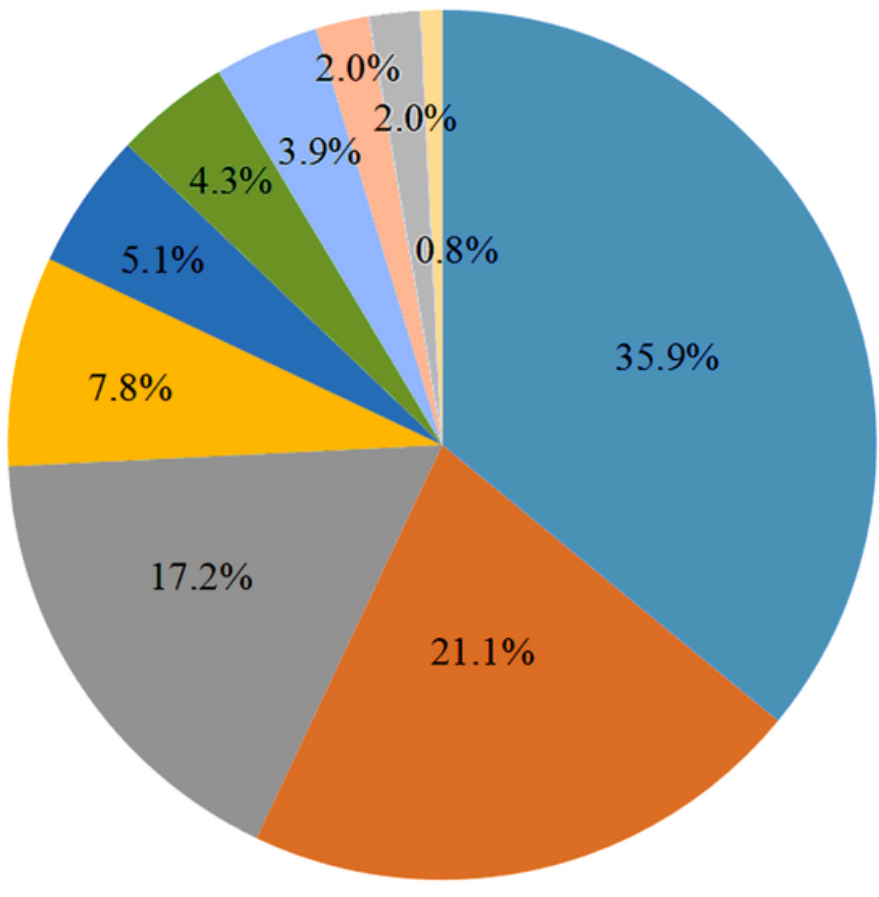

- Certain infectious and parasitic diseases

Diseases of the nervous system, mental and behavioural disorders

Diseases of the respiratory system

Endocrine, nutritional and metabolic diseases

- Diseases of the circulatory system

Diseases of the blood and blood-forming organs and certain disorders involving the immune mechanism

Diseases of the digestive system

Diseases of the skin and subcutaneous tissue

Neoplasms

External causes of morbidity and mortality 
Figure 5

Distribution of indications of research drugs $(n=256)$ 